\title{
El primer tropiezo histórico de Bonaparte: la reconquista de Santo Domingo*
}

\author{
Antonio J. PINTO \\ Universidad Europea de Madrid \\ antoniojesus.pinto@uem.es
}

Recibido: 20/07/2014

Aceptado: 07/09/2015

\section{RESUMEN}

El objetivo de este trabajo es estudiar el primer tropiezo histórico de las tropas de Napoleón Bonaparte, en Santo Domingo, y los paralelismos entre la Guerra de Independencia española y la Reconquista dominicana. Para ello se han analizado los testimonios de los personajes implicados, con el fin de indagar el ideario que inspiró su acción militar. Además probaremos que, contra las ideas defendidas por algunos historiadores, tras la paz de Basilea los dominicanos siguieron sintiéndose ligados a España, como demostraron en la Guerra de Reconquista contra el gobierno francés. Sólo Cuba, Puerto Rico y Santo Domingo participaron de este sentimiento, mientras el resto de Hispanoamérica comenzaba a clamar por la independencia.

Palabras clave: francofobia, Guerra de Reconquista, guerrilla, Jean-Louis Ferrand, Juan Sánchez, lealtad, Paz de Basilea, Santo Domingo.

\section{Bonaparte's First Setback: The Reconquest of Santo Domingo}

\begin{abstract}
This article's goal is to study the first failure of Napoleon Bonaparte's troops, which took place in Santo Domingo, and the mutual influence between the Peninsular War and Dominican Reconquest. I have analysed official declarations of the individuals that took part in the process, in order to find out the ideas that inspired the campaign on both sides of the battlefront. Thus I will prove that, unlike some historians have defended, Dominicans still felt linked to Spain after the Peace Treaty of Basel, as they proved in the War of Reconquest against France. Only Cuba, Puerto Rico, and Santo Domingo shared this experience, whereas the rest of Hispanic America started to claim for independence.
\end{abstract}

Key words: Franco-Phobia, Guerrilla, Jean-Louis Ferrand, Juan Sánchez, Loyalty, Peace Treaty of Basel, Santo Domingo, War of Reconquest.

\footnotetext{
${ }^{*}$ Esta investigación constituye una parte de mi tesis doctoral, Una colonia en la encrucijada: Santo Domingo, entre la revolución haitiana y la Reconquista española, 1791-1809, citada en la bibliografía y realizada como alumno de doctorado de la Universidad Complutense de Madrid y el Consejo Superior de Investigaciones Científicas, bajo la dirección de las doctoras Elena Hernández Sandoica e Inés Roldán de Montaud.
} 


\section{Abreviaturas}

AGI: Archivo General de Indias - Sevilla, España.

AHN: Archivo Histórico Nacional - Madrid, España.

TNA: The National Archives - Kew Gardens.

\section{Estado de la cuestión}

A mediados de octubre de 1795 se hizo efectiva la cláusula de la paz de Basilea en la que se disponía el abandono de Santo Domingo por la Corona española, que había hecho de ella su primera colonia en el Nuevo Mundo, pero que había renunciado a esta posesión para responder a las exigencias de Francia. Es preciso recordar que, en los años previos la Convención Nacional, había derrotado a España en la Guerra del Rosellón (1793-1795) y que, a cambio de no invadir la España peninsular, había exigido un territorio hispano de primera relevancia estratégica, como era el caso de Santo Domingo. Su paso a manos francesas no sólo suponía que el gobierno galo controlaría toda la Isla Española (Francia era de iure dueña de Saint-Domingue, actual Haití, desde 1697), sino también que Santo Domingo era susceptible de padecer el contagio de las ideas de la revolución francesa y, por ende, de la revolución esclava que había triunfado en Saint-Domingue, en la parte francesa de la isla, en 1791.

Uno de los temas controvertidos en torno a la historia de la revolución esclava de Saint-Domingue es precisamente la evolución que experimentó la mentalidad colectiva hispano-dominicana al calor de los desórdenes de la colonia vecina. Estos últimos acabaron contagiándose al propio territorio dominicano pese a los esfuerzos del gobierno colonial, encabezado por el capitán general Joaquín García. Todos los expertos en el periodo coinciden en resaltar, primero, el miedo generalizado ante la revolución esclava de Saint-Domingue entre los habitantes de Santo Domingo y, después, su indignación por el abandono de España en la paz de Basilea (1795), que les dejaba en manos de Francia y, sobre todo, de los esclavos rebeldes del oeste de la isla. A este respecto, han surgido dos corrientes de interpretación sobre las repercusiones de dicho tratado de paz en el ánimo de la población de Santo Domingo: por una parte, el historiador dominicano Frank Moya Pons, por ejemplo, ha analizado el dramatismo con que se vivió la firma de la paz de Basilea en Santo Domingo, centrándose en los aspectos indicados; ${ }^{1}$ investigaciones recientes, entre otros de Luis Alfonso Escolano y del autor del presente artículo, han reflejado el punto de inflexión que supuso dicho tratado de paz y sus consecuencias en el imaginario colectivo de los habitantes de la isla, que se sintieron abandonados por España, aunque nunca dejaron de identificarse a sí mismos como españoles antes que como dominicanos. ${ }^{2}$

\footnotetext{
1 MOYA PONS, Frank: "Casos de continuidad y ruptura: la revolución haitiana en Santo Domingo (17891809)", en Germán CARRERA DAMAS (dir.): La crisis estructural de las sociedades implantadas, "Historia general de América Latina”, vol. V, París, Editorial UNESCO, 2003, pp. 133-157.

2 ESCOLANO GIMÉNEZ, Luis Alfonso: "La guerra de Reconquista en Santo Domingo (1808-1809): una lucha por la continuidad histórica", Boletín del Archivo General de la Nación, XXXIV/125 (2009), pp. 635659; PINTO TORTOSA, Antonio Jesús: "La cultura popular hispano-dominicana ante la paz de Basilea: las décimas de Meso Mónica", Bulletin of Hispanic Studies, Liverpool, n. 98/8 (2013), pp. 921-944.
} 
Por otra parte, la corriente historiográfica que representan los dominicanos Emilio Cordero y Roberto Cassá, fundamentalmente, ha identificado la paz de Basilea como la fecha de nacimiento de la identidad dominicana: desangelada por el abandono de la que había sido su patria, los hispano-dominicanos se habrían desentendido de su antigua metrópoli y, según ambos autores, habrían buscado sus señas de identidad en la propia isla. Sin duda, el objetivo de Cordero y Cassá es reivindicar la identidad dominicana propia frente a las influencias externas. Por este motivo, entre otros, Emilio Cordero ha elogiado el gobierno del ex esclavo Toussaint Louverture en Santo Domingo (1801-1802), a la vez que ha reivindicado su contribución a la configuración del ser dominicano. ${ }^{3}$ Por su parte, Roberto Cassá ha señalado que el tratado de Basilea convenció a los dominicanos de la imposibilidad de obtener la ayuda española para combatir las amenazas externas, moviéndolos a defender sus intereses por sí mismos. Este último autor ha ido aún más lejos, negando la responsabilidad exclusiva del primer ministro de Carlos IV, Manuel de Godoy, en la firma de la paz de Basilea, probablemente para resaltar la implicación directa de la Corona y, de esta forma, identificar otro motivo de agravio de los dominicanos contra su antigua metrópoli; es decir, otro motivo para que los dominicanos de hoy identifiquen este momento con la génesis de su nación. ${ }^{4}$

Como puede verse la cuestión es delicada, ya que en el estudio de los orígenes de la identidad dominicana se mezclan, irremediablemente, intereses políticos y móviles ideológicos. Por ello y porque la Guerra de Reconquista, que enfrentó a los españoles dominicanos a la administración francesa de Santo Domingo durante dos años (18081809), constituyó una ocasión esencial en la que los diferentes intereses implicados en el proceso de construcción de una posible identidad dominicana se pusieron en liza, he considerado que merece la pena analizar dicho conflicto de manera atenta. Para ello, además de la documentación de época que cito a continuación, he tenido como marco de referencia estudios previos sobre la Guerra de Reconquista, entre los cuales cabe destacar la exhaustiva monografía de Fernando Picó: One Frenchman, Four Revolutions: General Ferrand and the Peoples of the Caribbean. ${ }^{5}$

En la presente investigación he analizado los diarios de campaña de los oficiales españoles y franceses durante la Guerra de Reconquista, librada entre 1808 y 1809 , junto con otros documentos de archivo de los protagonistas de este acontecimiento; entre los testimonios de época cabe destacar el diario de Juan Sánchez Ramírez, caudillo de la Reconquista, y las memorias de Gilbert Guillermin, estrecho colaborador del general Jean-Louis Ferrand, gobernador francés de la colonia, así como del capitán Jean Baptsite Lemonnier-Delafosse. ${ }^{6}$ El objetivo es valorar la posibilidad de

3 CORDERO MICHEL, Emilio: “Toussaint en Saint-Domingue espagnol”, en Alain YACOU (dir.): SaintDomingue espagnol et la révolution nègre d'Haïti. Commémoration du Bicentenaire de la naissance de l'état d'Haïti (1804-2004), Paris - Pointe-à-Pitre, Karthala - CERC, 2007, pp. 251-258.

4 CASSÁ, Roberto: "Les effets du Traité de Bâle", en Alain YACOU (dir.): Saint-Domingue espagnol et la révolution nègre d'Haïti. Commémoration du Bicentenaire de la naissance de l'état d'Haïti (1804-2004), Paris - Pointe-à-Pitre, Karthala - CERC, 2007, pp. 203-210.

5 PICÓ, Fernando: One Frenchman, Four Revolutions: General Ferrand and the Peoples of the Caribbean, Princeton - New Jersey: Marcus Wiener Publishers, 2012.

6 GUILLERMIN, Gilbert: Précis historique des derniers événements de la aprtie de l'est de SaintDomingue, depuis le 10 août 1808, jusqu'à la capitulation de Santo-Domingo, Paris, Chez Arthus-Bertrand, 
que la identidad dominicana verdaderamente no se hubiese forjado desde 1795 en adelante, contra lo sostenido por Cordero y Cassá, entre otros. Para formular esta hipótesis he tenido en cuenta, ante todo, que la insurrección de la población dominicana en 1808 contra la dominación francesa se hizo en nombre de España, con el fin de restaurar la soberanía española en aquella parte de la isla, mientras el resto de Hispanoamérica, a excepción de Cuba y Puerto Rico, comenzaba a luchar por su independencia; es decir, Santo Domingo constituyó un paradigma negativo en la América Hispana que es preciso explicar, en aras de clarificar el debate sobre los orígenes de la identidad nacional dominicana.

\section{La comunidad imaginada dominicana}

El concepto de "nación" es fundamental para entender por qué los habitantes de Santo Domingo se sublevaron contra la dominación francesa, representada por el general Ferrand, en agosto de 1808; justo cuando acababan de recibir las primeras noticias de la Guerra de Independencia española contra la dominación napoleónica.

Según Benedict Anderson, la "nación" tiene tres rasgos fundamentales: en primer lugar, es un término inventado y aplicado a una comunidad artificial; en segundo lugar, es un concepto limitado territorialmente: ninguna nación puede englobar a todos los seres humanos, ya que su ámbito de soberanía acaba donde empieza el de otras naciones vecinas; por último, es una comunidad cuyos miembros participan de un sentimiento de camaradería, que favorece su unión y su entrega al servicio de la patria. ${ }^{7}$ En la línea de Anderson, Eric J. Hobsbawm enfatiza la naturaleza imaginada de cualquier comunidad nacional y señala que, pese a construirse desde arriba por la élite intelectual y política, las naciones sólo pueden consolidarse desde abajo, gracias a la identificación de las masas con el ideal nacional. De ahí que los ideólogos nacionalistas se esfuercen en convencer al común de la población de que las preocupaciones "nacionales", que en origen pertenecen sólo a aquella élite, son las inquietudes de todos los miembros de esa nación. ${ }^{8}$

Por su parte, el historiador español José Álvarez Junco define la nación como cualquier grupo humano que cree compartir unas características culturales comunes y que, basándose en ellas, se cree legitimado para poseer y ejercer el poder político sobre un espacio físico concreto: bien un estado independiente, o bien una región autónoma dentro de una estructura estatal mayor. De esta forma, Álvarez Junco coincide con Anderson y Hobsbawm en destacar la comunidad de intereses de los integrantes de la nación, su disposición a entregar su vida al servicio de la patria y, por último, la relevancia del componente territorial para cualquier colectivo "nacional". Asimismo,

1811; SÁNCHEZ RAMÍREZ, Juan: Diario de la Reconquista, proemio y notas de fray Cipriano de Utrera, Ciudad Trujillo, República Dominicana, Editora Montalvo, 1957; LEMONNIER-DELAFOSSE, Jean Baptiste: Seconde Campagne de Saint-Domingue. Du ler Décembre 1803 au 15 Juillet 1809, Havre: Imprimerie de H. Brindeau \& Compagnie, 1846.

7 ANDERSON, Benedict: Imagined Communities. Reflections on the Origin and Spread of Nationalism, London - New York, Verso, 1991, p. 7.

8 HOBSBAWM, Eric: Naciones y nacionalismo desde 1780, Barcelona, Crítica, 2000, pp. 17-19. 
vuelve a llamar la atención sobre el carácter inventado de las naciones, que llega a tal extremo que los ideólogos nacionalistas deforman la realidad para adaptarla a los intereses de cada nación. ${ }^{9}$

Partiendo de estos postulados teóricos, ha de decirse que la configuración de la identidad dominicana durante los siglos XVI y XVII apenas distó de la definición de la identidad española en aquella misma época, que se cimentaba sobre cuatro pilares: la Corona, la religión, la lengua y el territorio. Todos los dominicanos se reconocían como súbditos del soberano español, profesaban la religión católica, hablaban en castellano y se consideraban integrantes del territorio español. Además Santo Domingo había sido la primera colonia de la Corona de Castilla en América y, puesto que España competía con otras potencias rivales por la colonización del Nuevo Mundo, sus habitantes siempre habían defendido su condición de baluartes de la identidad española al otro lado del Atlántico. A estos elementos añadieron un matiz "francófobo": dicho componente se hallaba presente en la metrópoli desde los años de tensión entre Carlos I y Francisco I, soberanos de España y Francia respectivamente. En cambio, no se hizo evidente en la Isla Española hasta mediados del siglo XVII, cuando los españoles que habitaban la isla y los bucaneros franceses que se habían asentado en el extremo occidental comenzaron a pugnar por el control del territorio, hasta que la firma de la Paz de Ryswick en 1697 sancionó la división de la isla en dos partes: Saint-Domingue, francés, al oeste, y Santo Domingo, español, al este. ${ }^{10}$

Lejos de tranquilizar la situación, dicho tratado de paz no hizo sino sembrar la semilla de la discordia en la isla, que en adelante sería escenario de constantes tensiones entre ambas zonas de dominación. Así pues, con el tiempo, la rivalidad con Francia acabaría siendo más fuerte entre los españoles dominicanos que entre los españoles peninsulares. Indudablemente esto se debió a que los españoles peninsulares habían respaldado las campañas de su rey en Europa contra las ambiciones francesas para afirmar la supremacía española en el viejo continente, para lo que no era necesario conquistar el territorio del enemigo, sino simplemente vencerlo en el campo de batalla. En cambio, los dominicanos necesitaban reconquistar el oeste y expulsar a los franceses de la Isla Española, pues de lo contrario corrían el riesgo de ser ellos los expulsados. En tales circunstancias, acabaron desarrollando una fuerte animadversión hacia Francia, luchando por el territorio palmo a palmo. Por ello el componente territorial de su identidad española fue tan fuerte, aunque ha de introducirse un matiz: a diferencia del nacionalismo clásico, caracterizado por su vertiente territorial centrífuga, la vis territorial del nacionalismo hispano-dominicano era centrípeta, es decir, su fin era reforzar al Imperio español en América en lugar de desmembrarlo. Llevados por la pasión propia de este tipo de discursos, los habitantes de la colonia exageraron el valor de Santo Domingo como supuesta piedra angular de Hispanoamérica, llegando a convencerse de que la pérdida de aquella colonia causaría un daño irreparable

9 ÁLVAREZ JUNCO, José: Mater Dolorosa. La idea de España en el siglo XIX, Madrid, Taurus, 2001, pp. 11-13.

10 GIMBERNARD, Jacinto: Historia de Santo Domingo, Madrid: M. Fernández y Cía., 1978, pp. 102107. 
a la monarquía, porque pondría de manifiesto su debilidad en el Nuevo Mundo y la convertiría en una presa fácil para sus rivales. ${ }^{11}$

La coyuntura descrita se agravó pronto: la rivalidad entre franceses y españoles se acentuó en Europa y América desde 1789 en adelante, cuando Francia se convirtió en la encarnación de la revolución y, por tanto, de todos los males imaginables, desde la óptica de sus enemigos europeos. Dicha actitud fue especialmente visible en La Española, donde se añadió un motivo ideológico a la rivalidad territorial hispano-francesa en el último siglo y medio. Aun así, lo peor estaba por llegar: la situación de los dominicanos se volvió especialmente dramática tras la revolución negra de Saint-Domingue de 1791, que no sólo amenazaba con llevar las ideas revolucionarias al Santo Domingo español, sino también con convertir aquel territorio en otro "cementerio blanco", al igual que la colonia vecina. A ello había que sumar el riesgo de contagio de los desórdenes de Saint-Domingue a otras colonias españolas donde los esclavos sí eran una pieza económica crucial, como por ejemplo (y sobre todo) Cuba. ${ }^{12}$

Desde la aparición de los primeros asentamientos franceses y, fundamentalmente, en medio de la crisis desatada desde 1791, los dominicanos siempre se habían mantenido fieles a España y habían defendido su colonia para preservar la integridad territorial española en América, exponiéndose a numerosos padecimientos. Por tanto, era lógico que esperasen alguna recompensa de su metrópoli. No obstante, la paz de Basilea les había devuelto a la cruda realidad, convenciéndoles de que su idea de la relevancia de Santo Domingo en el Imperio español era irreal, ya que cuando la Corona se vio obligada a elegir entre ceder aquella posesión ultramarina, o aceptar la pérdida de las plazas ocupadas por las tropas de la Convención en Cataluña, Navarra y las Vascongadas, no dudó en decantarse por la primera opción. Así el gobierno español demostraba que la preservación de la unidad territorial peninsular era prioritaria, pues con independencia del valor simbólico de Santo Domingo, las posesiones peninsulares constituían la auténtica base territorial de la monarquía española. Como consecuencia de ello, la paz de Basilea provocó una fuerte crisis en Santo Domingo, minando los pilares fundamentales de la identidad española de sus habitantes. ${ }^{13}$ Apar-

11 AHN, Estado, legajo 883, expediente 16. Instrucciones de la Corona al marqués del Socorro. Aranjuez, 12 de abril de 1795; LA PARRA, Emilio y LARRIBA, Elisabel (eds.): Manuel de Godoy. Memorias. Alicante: Universidad de Alicante, 2009, pp. 319-320. Las propias autoridades españolas habían dado cuenta de la relevancia estratégica de Santo Domingo para sus posesiones en Hispanoamérica, puesto que el embajador español presente en las negociaciones de la paz de Basilea se había resistido mucho a incluir Santo Domingo como moneda de pago a cambio de la paz con Francia. Por su parte, Manuel de Godoy remitió las siguientes instrucciones al marqués del Socorro, encargado de evacuar a la población de Santo Domingo a Cuba, para que Santo Domingo fuese destruida tras la marcha de los españoles dominicanos, a fin de que nadie pudiese aprovecharse ni de sus recursos ni de su posición estratégica en el Caribe (en ésta y en todas las citas textuales he preservado la ortografía original del texto citado): El rey renunciará a sus derechos sobre la poseción de la ysla quando sea que no puede ser defendida y en este caso después de salvados los abitantes de ella y trasladados a la de Cuba, quiere que se le prenda fuego y se ocupa el exército en sola esta empresa no quiere ceder su derecho a condiciones que propongan los gefes yngleses ni que éstos queden en la ysla cuando $\mathrm{Su}$ Majestad la abandone.

12 GONZÁLEZ CALLEJA, Eduardo: “España 'Boba', España 'Cavalera' y España 'Madre y Maestra': las relaciones hispano-dominicanas en la conformación de as respectivas identidades nacionales”, Clío, 80/182 (2011), p. 230.

13 LEMONNIER-DELAFOSSE, Jean Baptiste: Seconde Campagne..., pp. 189-190. Aquí se recogen de manera sintética las condiciones de la Paz de Basilea. 
te de su impacto territorial, fue traumática la desaparición de la tradición monárquica, puesto que Francia, nueva poseedora de Santo Domingo, era una República. Momentáneamente sólo resistieron el envite la lengua castellana y la religión católica, pero las autoridades francesas sólo las respetaron en apariencia para ganarse el afecto de los dominicanos. Cuando estos últimos confiasen en ellas ciegamente, les impondrían su propia cultura para borrar cualquier trazo de identidad española. De ello da testimonio la actitud del comisario francés Philippe-Rose Roume de Saint-Laurent, cuya aparente amistad identificó el arzobispo de Santo Domingo como una mera artimaña para tranquilizar a la población dominicana sobre el respeto a la religión católica. ${ }^{14}$ Como revela en una carta a Godoy localizada en el Archivo General de Indias, fray Fernando Portillo no dudaba de que, una vez ganada la población de la colonia, Roume depondría su actitud y anularía también la religión católica de aquel territorio.

Ahora bien, pese a la catástrofe que había supuesto el tratado de paz para los dominicanos, que se convirtieron en ciudadanos de su principal enemigo y, además, de la patria de la revolución, todos aparentaron aceptar la administración gala de buen grado. Haciéndolo, demostraban su obediencia al rey español hasta el final, aunque la última decisión de su soberano les hubiese perjudicado claramente. ${ }^{15} \mathrm{Su}$ actitud se entiende, además, porque carecían de fuerzas suficientes para resistir la ocupación francesa, pese a que hubo algunos focos insurgentes que fueron duramente reprimidos. Así pues, el instinto de supervivencia se impuso en la población dominicana, consciente de que la "solución francesa" era la única alternativa posible a dos desenlaces que ellos rechazaban: la dominación británica, porque Gran Bretaña era enemiga de España desde la firma de la paz con Francia y, sobre todo, la dominación negra, que sólo las fuerzas republicanas galas podían contrarrestar. Incluso quienes colaboraron con la administración francesa, como el futuro caudillo de la Guerra de Reconquista, Juan Sánchez Ramírez, conspiraron en secreto a favor de España. ${ }^{16}$ Sin embargo, hubo quien simpatizó sinceramente con la nueva administración francesa,

14 AGI, Estado, legajo 11A, expediente 9, documento 1. Informe de fray Fernando Portillo al Príncipe de la Paz sobre las maniobras de Roume para conseguir que el arzobispo se quedase en la colonia, y para ganar adeptos entre la población dominicana. Santo Domingo, 4 de mayo de 1796. Las circunstancias de la isla obligaron a los franceses a aceptar el prestigio de los ministros de la Iglesia entre los dominicanos, aunque no lo hicieron movidos por su afán de tolerancia, sino por la conciencia de que los necesitaban para mantener a la población dominicana tranquila. Cuando los ánimos se hubiesen calmado, procederían a la aculturación masiva de los habitantes del lugar; CORDERO MICHEL: "El primer intento independentista dominicano y la reincorporación a España, 1808-1809”, Clio, 79/180, pp. 126-127.

15 AGI, Estado, legajo 13, documento 1. Representación de los miembros del cabildo de Santiago de los Caballeros al capitán general Joaquín García. Santo Domingo, 25 de octubre 1795. Estos últimos se limitaron a reprochar a la Corona su decisión de entregar Santo Domingo a Francia en los siguientes términos: “¿Y qué dolor tendrá Vuestra Majestad en perder a unos vasallos que le han dado hasta el último suspiro, tan repetidas pruebas de su fidelidad?". Por añadidura, acusaron a España de comprar la paz "con lágrimas de sangre". Sin embargo, en buena medida el dramatismo de estas declaraciones se entiende porque el regidor que encabezaba este manifiesto, Tiburcio José de Sterling, había llegado a Santo Domingo huyendo de Saint-Domingue. Por tanto, necesariamente debió espantarse de la paz de Basilea, que convirtió Santo Domingo en caldo de cultivo de la misma ideología revolucionaria y del espíritu insurreccional esclavo de los que él había pretendido escapar.

16 AHN, Estado, legajo 59, expediente 14, documento 8. Informe del general francés Kerversau al ministro de Marina y las Colonias de Francia. 8 de septiembre de 1800. 
como dos autoridades representativas de Santiago de los Caballeros, Joaquín Pueyo y Francisco Gazcue, quienes merecieron por ello el desprecio de sus convecinos. ${ }^{17}$

En adelante, las calamidades acaecidas en Santo Domingo tuvieron dos efectos distintos: por una parte, contribuyeron a incrementar el resentimiento dominicano contra el ejecutivo español, que les había abandonado en manos de Francia; por otra, reforzaron la lealtad de los habitantes de la colonia a la monarquía, convencidos de que la firma de la paz había sido obra de los políticos corruptos, en concreto de Manuel de Godoy, que en su opinión había obrado a espaldas del monarca. ${ }^{18}$ El gobierno colonial de Santo Domingo, español al servicio de Francia, junto con algunos intelectuales y muchas figuras representativas de la cultura dominicana sabían que aquella imagen de la monarquía era idílica, porque en última instancia había sido el rey quien había rubricado el acuerdo de paz. No obstante, también eran conscientes de que sólo la lealtad al rey aglutinaría a todos los dominicanos y les mantendría fieles a España, librándolos del contagio de las ideas revolucionarias. Por tanto, en adelante todos estos miembros de la élite gubernamental participaron en una hábil campaña propagandística para explotar la imagen del "monarca benefactor" y hacer que calase hondo en la mentalidad dominicana. Entre todos ellos se destacó Manuel Meso Mónica, cuyas décimas tras la firma de la paz de Basilea he estudiado en la investigación reseñada al comienzo de este artículo. ${ }^{19}$

\section{Génesis de la Guerra de Reconquista}

El líder de los patriotas dominicanos sublevados contra el gobierno francés fue el hacendado Juan Sánchez Ramírez. ${ }^{20}$ Hasta la publicación de la paz de Basilea este individuo, descendiente de una familia de propietarios de tierras, había ejercido el cargo de corregidor en su villa natal de Cotuí, junto con otras funciones públicas. ${ }^{21}$ Al principio permaneció bajo bandera francesa, pero en diciembre de 1803 abandonó la isla, probablemente motivado por la inminente proclamación de independencia de la República negra de Haití que tuvo lugar el 1 de enero de 1804, días antes de su desembarco en Puerto Rico. Sin embargo, como dejó todas sus posesiones atrás y su posición socioeconómica en Puerto Rico llegó a ser bastante precaria, Sánchez acabó regresando a Santo Domingo en $1807 .^{22}$

Desde su regreso, Juan Sánchez vivió dedicado a la explotación de caoba en el sur de la colonia y a la ganadería. Sus intereses económicos se vieron perjudicados cuando el capitán general Ferrand prohibió el comercio de reses en la frontera entre

\footnotetext{
17 AGI, Estado, legajo 11A, expediente 9, documento 1. Informe de fray Fernando Portillo...

18 MOYA PONS: "Casos de continuidad...", pp. 156-157.

19 PINTO TORTOSA: "La cultura popular...".

20 ARTOLA, Miguel: "La guerra de Reconquista de Santo Domingo (1808-1809)", Revista de Indias, Madrid, LI/191 (1951), pp. 447-484. Pese a su fecha, este artículo constituye un estudio detallado de la campaña de los hispano-dominicanos para restablecer la soberanía española en Santo Domingo.

21 SÁNCHEZ RAMÍREZ: Diario..., n. 2.

22 SÁNCHEZ RAMÍREZ: Diario..., p. 2.
} 
Haití y Santo Domingo. ${ }^{23}$ Agraviado por esta circunstancia, y espoleado por la noticia del secuestro de la familia real de España en Bayona por Napoleón Bonaparte, Sánchez tomó la determinación de aprovechar las circunstancias y encabezar una sublevación armada contra el gobierno francés en Santo Domingo. ${ }^{24}$ Sobre el papel, la sublevación tramada por Juan Sánchez significaría un acto de alta traición al Imperio Francés, ${ }^{25}$ puesto que Santo Domingo pertenecía a este último desde la Paz de Basilea. Sin embargo, el hacendado asumió los riesgos y decidió seguir adelante con los preparativos, confiado en la lealtad tradicional de los dominicanos a su antiguo rey:

Desde aquel momento no pude sacudir de la imaginación la idea de la guerra, que suponía ya como evidente contra los segundos [los franceses], y aquel encuentro [con el comandante de Sabana de la Mar] produxo en mi espíritu tal encono contra ellos, que, a pesar de la aceptación que les debía hasta llamarme ellos mismos el amigo de los franceses, no podía verlos ya desde entonces sin irritarme en extremo. ${ }^{26}$

En las semanas siguientes, compaginó sus ocupaciones cotidianas con las tareas conspirativas, con la convicción de que era necesario persuadir a la población hispano-dominicana de que se sumase al esfuerzo bélico; mientras tanto, en la España peninsular la Junta de Sevilla se decidía a declarar la guerra a Francia oficialmente. La noticia llegó a Santo Domingo en julio de 1808 y Sánchez la comunicó inmediatamente a su principal socio, Manuel Carvajal. ${ }^{27}$ Inmediatamente después marchó a la capital de la colonia, so pretexto de entrevistarse con Ferrand para tratar con él sobre sus negocios ganaderos y de caoba, y aprovechó el trayecto hasta la ciudad de Santo Domingo para ganar adeptos a la conspiración por el camino. Una vez arribado a su destino redobló su labor propagandística con los habitantes de la capital, consciente de que la conquista de esta plaza pondría toda la colonia a su disposición. ${ }^{28}$ Sus acciones se revelaron harto complejas, ya que los vecinos de la ciudad de Santo Domingo habían sufrido directamente las consecuencias del "abandono español" tras la paz de Basilea, de modo que preferían preservar el statu quo a luchar por la restauración de la lejana monarquía española, que ya les había traicionado y podía volver a hacerlo.

23 CORDERO MICHEL, Emilio: "El primer intento...”, pp. 123-124. Este autor argumenta que la situación económica ruinosa de Santo Domingo se remonta más allá de las prohibiciones de Ferrand, entre otros motivos porque buena parte del comercio ganadero y de caoba dominicano se hacía con Inglaterra, que bloqueó Santo Domingo tras la restauración del poder francés en la colonia en 1802 .

24 SÁNCHEZ RAMÍREZ: Diario..., p. 3. La noticia del secuestro de la familia real en Bayona debió conocerla cuando se encontraba en Sabana de la Mar, atendiendo unas gestiones personales.

25 Es preciso aclarar que Francia poseía un régimen republicano en 1795, cuando se firmó la paz de Basilea, pero en 1808, momento al que se refieren estas líneas, ya se hallaba inmersa en pleno Imperio Napoleónico.

26 SÁNCHEZ RAMÍREZ: Diario..., p. 4. La cursiva aparece en el original. Su condición de "amigo de los franceses", que él mismo había reconocido, demostraba su actitud aparentemente cordial hacia los nuevos gobernantes de Santo Domingo. Ésta no necesariamente significaba una sincera adhesión a Francia, sino que podía ser una actitud impostada para ganarse la confianza de los franceses y conspirar contra ellos sin suscitar sus sospechas. Fernando Picó, en su admirable trabajo sobre la figura de Ferrand y su administración en la isla, señala que la comunicación oficial del general francés a los habitantes de Santo Domingo tuvo lugar el 9 de agosto. PICÓ: One Frenchman...

27 SÁNCHEZ RAMÍREZ: Diario..., p. 7. El capitán general de Puerto Rico, Toribio Montes, comunicó la noticia oficialmente a Jean-Louis Ferrand, gobernador de Santo Domingo, el 2 de agosto de 1808.

28 SÁNCHEZ RAMÍREZ: Diario..., pp. 9-10. 
Tras comprobar su éxito limitado entre la población de Santo Domingo, Juan Sánchez se mantuvo fiel a su propósito de ganar adeptos para su causa, pero en adelante se sirvió de dos instrumentos clave: el clero, cuyo ascendente ideológico sobre las masas era esencial, y los militares españoles, muchos de ellos servidores de Francia sólo nominalmente, porque representaban un apoyo decisivo si se contagiaban del espíritu insurreccional de los "patriotas españoles" de la Península Ibérica, ya que podían conspirar contra el gobierno francés desde dentro. Ello nos lleva a considerar que, contando con estos últimos, Juan Sánchez recurrió a una peligrosa arma de doble filo, ya que los militares coloniales también podían delatarlo ante Ferrand y ordenar su arresto. De ello da fe la denuncia del comandante de La Vega y hombre de confianza de Ferrand, Agustín Franco, con quien Juan Sánchez se había entrevistado y que no dudó en delatarle ante el gobernante de Santo Domingo. ${ }^{29}$ Pese a todo, Sánchez debió juzgar que, si conseguía la adhesión sincera de los militares franceses, los beneficios serían tan grandes que valía la pena arriesgarse. Con esta convicción prosiguió su labor de proselitismo itinerante por el interior y la costa de Santo Domingo. ${ }^{30}$

Con el tiempo, las autoridades francesas fueron estrechando el cerco de vigilancia sobre Sánchez y éste debió refugiarse en la ensenada de Jayán, de difícil acceso para tropas poco experimentadas en el terreno. Sólo cuando el capitán general de Puerto Rico, Toribio Montes, le comunicó que estaba dispuesto a prestarle su apoyo material para la campaña, el líder de la Reconquista retomó la lucha armada contra los franceses. ${ }^{31}$ A finales de septiembre de 1808 la insurrección comenzó a extenderse desde El Seibo y numerosas villas se sumaron a los vivas a Fernando VII. Fue entonces cuando Ferrand, que al principio se había limitado a seguir de cerca los movimientos de Juan Sánchez y sus hombres, acabó interpretando las adhesiones crecientes a los insurrectos como una declaración de guerra velada. Por consiguiente, en adelante no le tembló el pulso y respondió a la violencia de los conspiradores con la violencia de su ejército. ${ }^{32}$

29 SÁNCHEZ RAMÍREZ: Diario..., pp. 10-12.

30 He utilizado el término "patriota" para referirme a los habitantes de Santo Domingo que combatieron a Francia, por paralelismo con los "patriotas" que se sublevaron contras las tropas napoleónicas en la España peninsular.

31 SÁNCHEZ RAMÍREZ: Diario..., pp. 27-28.

32 GUILlERMIN, Gilbert: Précis historique..., p. 43. Como se ha visto, los franceses conocían a la perfección los preparativos ocultos de los patriotas dominicanos, hasta el extremo de asediar a Sánchez Ramírez y estar a punto de detenerlo para abortar el complot. No obstante, en lugar de intervenir decidieron esperar a que los conspiradores cometiesen la primera agresión armada, porque entonces podrían apelar al derecho de legítima defensa para contraatacar, tachando a los patriotas hispano-dominicanos de reos de lesa majestad. Piénsese que los habitantes de Santo Domingo eran franceses de iure desde 1795 y de facto desde 1802, de modo que la acusación como culpables de alta traición estaba más que justificada, desde la óptica francesa. LEMONNIER-DELAFOSSE, Jean Baptiste: Seconde Campagne..., p. 193. Aquí se recoge un discurso de Ferrand, indignado por el éxito de la conspiración de Sánchez, animando a los franceses a iniciar una guerra sin cuartel contra los rebeldes dominicanos. 


\section{De Madrid a Santo Domingo}

Los últimos sucesos acaecidos en suelo dominicano estaban estrechamente ligados al devenir reciente de la España peninsular y guardaban algunas similitudes con la Guerra de Independencia, aunque también presentaban ciertas diferencias significativas. Entre las similitudes cabe destacar el peso de la identidad española en los hispano- dominicanos para iniciar la sublevación contra los franceses, ya que en aquella identidad existía un importante componente "francófobo", como se ha señalado previamente. En el caso de los habitantes de Santo Domingo, dicho sentimiento era muy acusado por la convivencia tensa con los franceses en la Española durante casi un siglo y medio. En paralelo, aunque en la Península Ibérica la francofobia había pervivido durante toda la Edad Moderna, se había reforzado tras la invasión napoleónica en 1807, que había concienciado a sus habitantes de la amenaza territorial real francesa.

Asimismo, los españoles dominicanos se habían considerado depositarios del poder del rey, "usurpado" por la Convención Nacional en la paz de Basilea. Este dato es esencial, puesto que los súbditos de Fernando VII esgrimieron este mismo argumento en 1808 para justificar su sublevación contra la dominación francesa en la metrópoli. En el caso de los hispano-dominicanos aquella justificación carecía de fundamento: Carlos IV había renunciado a Santo Domingo voluntariamente, mientras que Fernando VII había sido depuesto por las tropas francesas por la fuerza. Sin embargo, ellos interpretaron la paz de Basilea como una transacción de poder de un rey justo, el español, a una nación soberana tiránica, la francesa. De esta forma, conectaron con los arbitristas barrocos y los pensadores ilustrados europeos, convenciéndose de que en aquellas circunstancias eran los depositarios de la autoridad usurpada de los reyes de España. ${ }^{33}$ Por consiguiente, aguardaron el momento adecuado para sublevarse contra su nuevo "señor" despótico, Francia, arrebatarle el poder y devolvérselo a su legítimo dueño. Así pues, la Reconquista dominicana establecía una clara continuidad con el pasado, ya que sus abanderados se habían erigido en depositarios de la soberanía de los reyes españoles en Santo Domingo durante los casi tres últimos lustros de dominación francesa.

La tercera semejanza radicó en la importancia de la estrategia de guerrilla, única posible frente a los franceses, que partían de una posición ventajosa en tanto que gobierno dominicano legítimo. Primero, los patriotas conquistaron el terreno palmo a palmo desde la óptica ideológica, gracias al periplo de Juan Sánchez estudiado previamente. Conseguida la adhesión de la mayoría de los habitantes de la colonia, con el recelo de los vecinos de la capital, se dio el paso hacia la guerrilla territorial. Aparte de la posición inferior de partida de los rebeldes, también hubo en Santo Domingo otros rasgos de la guerrilla peninsular, estudiada por Miguel Artola; a saber: la dispersión de las fuerzas rebeldes, que dificultó la labor de coordinación de Sánchez, pero permitió a los patriotas eludir fácilmente la vigilancia francesa; el peso de la iniciativa individual, encarnada por el propio Juan Sánchez; el apoyo crucial de la

33 SPINOZA, Benedictus de: Tratado teológico político (ed. de Julián de Vargas y Antonio Zozaya). 3 vols. Madrid: Sociedad General Española de Liberaría, 1935 [1670]; ROUSSEAU, Jean-Jacques: Del contrato social: sobre las ciencias y las artes; sobre el origen y los fundamentos de la desigualdad entre los hombres (ed. Mauro Armiño). Madrid: Alianza, 2002 [1762]. 
población, beligerante en buena medida, habida cuenta de que respaldó a los rebeldes de diversas formas, tanto humanas como materiales; el enconamiento de la postura de los rebeldes conforme se intensificó la represión francesa; y por último, la voluntad manifiesta de los patriotas de enfrentarse a los franceses sólo en campo abierto, exclusivamente cuando estaban seguros de su victoria, puesto que su objetivo no era derrotar al enemigo en el campo de batalla, sino minar su moral mediante una larga guerra de desgaste. ${ }^{34}$

Una diferencia fundamental entre la coyuntura española y la hispano-dominicana estribó en que en Santo Domingo no existieron las juntas, que en la España peninsular habían funcionado como representantes del poder popular y depositarias de la soberanía de Fernando VII, usurpada. Esta circunstancia se explica porque, a diferencia de la Península, en Santo Domingo no existió un vacío de poder propiciatorio de una explosión "juntista", sino que Francia era la soberana legal desde 1795. ${ }^{35}$ Esto además implicaba que, mediante la insurrección, los dominicanos cometían un doble desacato: por una parte, desautorizaban a Carlos IV, que les había entregado a Francia; por otra, ya que la paz de Basilea había convertido a los dominicanos en franceses, si se sublevaban contra Francia serían considerados reos de lesa majestad, como el propio Ferrand les recordó: "[...] todos vosotros os habéis convertido en franceses; o quizá en franceses y españoles; no constituimos más que un único pueblo de hermanos y amigos, que no defienden más que un mismo interés, y que no profesan más que un único espíritu y unos mismos sentimientos". ${ }^{36}$ Además, la ausencia de las juntas también se habría debido a que los dominicanos recelaban de su componente de soberanía popular, de reminiscencias liberales y, por consiguiente, opuestas a su deseo de restablecer el Antiguo Régimen en Santo Domingo.

La segunda diferencia reseñable, que conecta con la idea anterior, fue la ausencia del componente liberal de la Guerra de Independencia. Los españoles dominicanos habían definido su identidad sobre la base de la lengua, el territorio y, sobre todo, la monarquía y la religión, opuestas a los valores subversivos triunfantes en Francia. Por consiguiente, desde su punto de vista, el liberalismo de algunos miembros de las juntas peninsulares era heredero de los principios que habían inspirado a los revolucionarios franceses, que ellos rechazaban frontalmente. Además, estaban convenci-

34 ARTOLA, Miguel: La burguesía revolucionaria (1808-1875), "Historia de España", vol. 5, Madrid: Alianza, 1990, pp. 32-33; FONTANA I LÁZARO, Josep, La época del liberalismo, "Historia de España", vol. 6, Barcelona: Crítica, 2007, pp. 45-46; CORDERO MICHEL: "El primer intento...", p. 135. En este artículo, Emilio Cordero destaca los medios de combate de los dominicanos, consistentes en el uso del arma blanca (machete criollo y lanza de vaquero), como clave de la victoria contra las tropas francesas, numérica y militarmente superiores.

35 GUERRA, Adriano Israel: "Las paradojas de la soberanía y el poder: Santo Domingo durante la Revolución Haitiana y su representación en las Cortes de Cádiz”, Clio, n. 81/184 (2012), pp. 11-98. En realidad, en Santo Domingo los rebeldes patriotas sí celebraron una junta en Bondillo, en noviembre y diciembre de 1808, que queda registrada en los Diarios de Juan Sánchez (pp. 103-104) y que ha registrado Guerra en la investigación aquí citada. No obstante, el propósito de dicha junta fue, ante todo, resolver problemas internos del ejército patriota, más allá de tratar la representación de los patriotas hispano-dominicanos en el contexto de las Cortes de Cádiz; CORDERO MICHEL: "El primer intento...", pp. 137-144.

36 GUILLERMIN: Précis historique..., p. 37: "[...] vous êtes tous devenus François; ou plutôt François et Espagnols, nous ne formons ensemble qu'un peuple de frères et d'amis, qui n'ont que le même intérêt à défendre, le Même esprit et les Mêmes sentiments à professer" 
dos de que el liberalismo y la abolición de la esclavitud iban irremisiblemente unidos. Así pues, pese a que la mano de obra esclava tenía menor peso en Santo Domingo que en otras partes de Hispanoamérica, los hacendados no estaban dispuestos a ser víctimas de sus esclavos, en el supuesto de que un eventual gobierno liberal decretase su liberación. Por tanto, el eco de la revolución haitiana también pesó significativamente en su postura. ${ }^{37}$

\section{Desarrollo del conflicto hasta la batalla de Palo Hincado}

Juan Sánchez planeó avanzar con rapidez hacia el este con el fin de aislar la ciudad de Santo Domingo cuanto antes; objetivo este último que consiguió el 28 de septiembre, tras cortar la comunicación entre la capital y la bahía de Samaná, que constituía un enclave estratégico fundamental de comunicación con el exterior. ${ }^{38} \mathrm{La}$ posesión de esta última garantizó a los insurrectos el aprovisionamiento de víveres y demás medios materiales, privando a Francia de un puerto de condiciones naturales excepcionales. A finales de septiembre los rebeldes conquistaron Barahona, en la que fue considerada por los franceses como la primera acción real de la Guerra de Reconquista. ${ }^{39}$ Desde aquí se organizó la expedición que puso a disposición de los patriotas las plazas de Azua, Neiba y Las Matas, entre otras. De esta forma, un mes más tarde los insurgentes controlaban todo el sector occidental del antiguo Santo Domingo español.

Ahora bien, no todo fueron victorias y buenos augurios para los patriotas hispanodominicanos, que sufrieron bajas notables y deserciones. Hasta entonces el gobierno colonial francés había sido magnánimo con los prisioneros de guerra y con los vencidos en sus victorias pírricas contra los rebeldes, pero la tenacidad del enemigo le hizo cambiar de actitud y, en adelante, represalió duramente a los cautivos para castigar su deslealtad a Francia. El autor material de las penas más duras fue un estrecho colaborador de Ferrand, el coronel Aussenac, quien el 22 de octubre quemó las viviendas aledañas de San Juan, recientemente reconquistado por Francia. Así, Aussenac no sólo castigaba a los conspiradores contra el gobierno francés, sino que también destruía la cosecha y dificultaba el aprovisionamiento de los patriotas, que deberían desplazarse a lugares más alejados para proveerse de avituallamiento; por consiguiente, se verían obligados a ralentizar su marcha. ${ }^{40}$ Sin embargo, el recrudecimiento represivo fue contraproducente para los franceses porque alimentó el odio de los dominicanos hacia ellos, dando alas a la causa patriota, que obtuvo adhesiones en enclaves cuya población le había sido esquiva hasta entonces.

37 AHN, Estado, legajo 3407 (1). Informe de Joaquín García a la Corona. Santo Domingo, 19 de noviembre de 1795. Valga como muestra del recelo de los españoles dominicanos a los supuestos males de la revolución y del liberalismo esta declaración del gobernador García, que revela su apego (y el de sus gobernados) al Viejo Orden: Contemplo también que al llegar el General Francés con sus tropas ha de introducirse el horror, y la confusión en un vecindario que no está acostumbrado a ver dos borrachos juntos, ni otros sentimientos y efectos que los del Orden, y de libertad, solos los que permite la civil y christiana.

38 SÁNCHEZ RAMÍREZ: Diario..., pp. 32-33.

39 SÁNCHEZ RAMÍREZ: Diario..., pp. 43-44.

40 GUILLERMIN: Précis historique..., p. 59. 
La guerra se mantuvo en el estado descrito, con avances y retrocesos por parte de ambos bandos, hasta noviembre de 1808. A principios de dicho mes un tránsfuga del bando patriota informó al coronel Aussenac de que los rebeldes habían conquistado el campo de Tavares, a seis leguas de Azua. Para ello, se habían servido de un ejército de 300 soldados de caballería y 200 mulatos o negros franceses. Aussenac reaccionó rápidamente y marchó de Azua, que juzgaba difícil de defender, para concentrar las tropas de aquella plaza en Savane-Buey, a una legua del río Ocoa. La situación de las tropas francesas no era nada halagüeña, ya que estaban exhaustas por la guerra de desgaste y diezmadas por la imposibilidad de contar con el apoyo de la banda oriental de Santo Domingo, que se había sublevado también contra su soberanía. ${ }^{41}$ No obstante, parece ser que la rabia pudo a la templanza y el general Ferrand respondió a la amenaza impulsivamente, poniéndose al frente de una expedición de 500 hombres para hacer frente a los patriotas. A todas luces su iniciativa fue fatal: jamás consideró la posibilidad de que su marcha al frente debilitara en demasía las defensas de la capital, que perdían efectividad sin su talento militar y sin la guarnición que él se llevó consigo a primera línea de combate. Antes de partir, Ferrand dirigió una proclama a los habitantes de la ciudad de Santo Domingo, que le habían implorado que no les abandonase. En dicha proclama les advertía de que los patriotas y sus partidarios representaban la subversión del orden vigente en la isla de la Isla Española, sancionada por la paz de Basilea. Asimismo, manifestó que si los franceses llegaban a ceder Santo Domingo a España nuevamente sólo lo harían mediante tratados pacíficos, pero jamás presionados por una acción violenta del enemigo. ${ }^{42}$

Ferrand seguía sin explicarse cómo los patriotas pudieron haber encontrado tanto apoyo entre los dominicanos, a quienes la administración francesa había intentado atender y gobernar con justicia desde $1802 .{ }^{43}$ Como su situación era ahora especialmente crítica, decidió amenazar con una dura represión a quienes traicionasen a Francia en adelante. ${ }^{44}$ La novedad de esta última iniciativa radicaba en que, a diferencia de la represión previa, que sólo afectaba a las tropas patriotas, el castigo ahora se extendería a toda la población de los enclaves sublevados contra el gobierno legítimo. De esta forma, demostraba haber tomado conciencia de que la estrategia de guerrilla, usada por los patriotas, significaba que toda la población era beligerante, aunque no toda fuese combatiente. ${ }^{45}$ Casi con toda seguridad, la represión de los civiles le habría planteado serias dudas éticas hasta entonces, ya que aquellos individuos habían colaborado con el enemigo, pero carecían ellos mismos de armas para defenderse de los franceses, por lo que si las tropas imperiales decidían atacarles partirían de una indudable posición de superioridad. Para solucionar esta cuestión ética, el general francés se eximió a sí mismo y a sus hombres de responsabilidad, advirtiendo que los responsables de aquel castigo eran sólo los propios dominicanos, que habían des-

41 GUILLERMIN: Précis historique..., pp. 60-61.

42 GUILLERMIN: Précis historique..., pp. 62-63.

43 CORDERO MICHEL: "El primer intento...", pp. 124-125.

44 GUILLERMIN: Précis historique..., p. 64.

45 Estimo que la naturaleza combatiente implica la confrontación directa con el enemigo, mientras que la beligerancia es una idea que engloba también varios ejemplos de lucha y resistencia pasiva, tales como el suministro de víveres a los rebeldes, el boicot a los servicios prestados por la administración francesa, etc. 
preciado a su gobierno legítimo. Al mismo tiempo, prometió recompensar a quienes permaneciesen fieles a Francia. ${ }^{46}$

El 4 de noviembre el gobernador francés reunió sus tropas en El Seibo para coger al enemigo desprevenido. Tres días después remitió un ultimátum a Sánchez, manifestando su intención de resistir hasta el final, amparado en la superioridad numérica de sus hombres. La respuesta del general Sánchez no se hizo esperar y en ella encarnó los valores esenciales de la conciencia prenacional española: el caudillo hispanodominicano manifestó al alto mando francés la voluntad de combatir sin cuartel al enemigo para expulsarlo de la isla y la disposición a dar la vida por la madre patria. Además, en su respuesta oficial Sánchez se denominó a sí mismo capitán general de Santo Domingo, de modo que desautorizaba al gobierno colonial francés, único legítimo en el este de la isla desde la paz de Basilea. Oídas las razones de Sánchez, Ferrand se convenció de que el acuerdo pacífico era imposible y atacó a los patriotas el 7 de noviembre, en la batalla de la sabana de Palo Hincado.

Justo antes de que se produjese el choque, Juan Sánchez había arengado a sus tropas y les había recordado la necesidad de vencer a los súbditos de Napoleón Bonaparte, que encarnaban unos valores radicalmente opuestos a los de los españoles. Igualmente, les hizo ver que su victoria en aquella batalla tendría graves repercusiones para el gobierno colonial francés, porque el propio capitán general Ferrand estaba al frente de las tropas y podía ser apresado o muerto en la refriega, dejando así la colonia descabezada. Sánchez demostró un gran sentido común y un experimentado conocimiento de la estrategia militar: obviamente era consciente de que los franceses eran superiores en el cuerpo a cuerpo, aunque sus recursos eran limitados y sus tropas menos numerosas. Por este mismo motivo, ordenó a los soldados patriotas que los dejasen avanzar hasta la primera descarga de fusilería; entonces los enemigos estarían suficientemente cerca para emplear la artillería patriota contra ellos y romper sus filas. Por último, previno a sus hombres contra la tentación de desertar, describiendo el duro castigo que aguardaba a los traidores: "Pena de la vida al que bolviere la cara atrás; pena de la vida al tambor que tocare retirada; y pena de la vida al oficial que lo mandare, aunque sea yo mismo". ${ }^{47}$ Todos respondieron a su discurso entusiasmados, profiriendo vivas a Fernando VII.

Concluida la arenga de Sánchez, los patriotas oyeron a las tropas francesas aproximarse. Siguiendo las instrucciones de su general, aguardaron hasta que estuvieron suficientemente cerca para atacarlas. Llegado el momento, "echándosele el quién vive, y respondiendo francés, con el ademán de comenzar a desplegar en batalla,

\footnotetext{
${ }^{46}$ GUILLERMIN: Précis historique..., pp. 66-68. Guillermin resumió el espíritu que había inspirado tales iniciativas de Ferrand en la siguiente máxima: "Si toutes les vertus qui constituent l'honnêteté homme et le bon chrétien, obtiennent ainsi le prix qui leur est dû, le crime et la scélératesse obtiendront, je le répète, la punition que commandent les mêmes principes d'équité et de justice". Aunque esta medida de Ferrand parecía indicar que había tomado conciencia del alcance de la estrategia de guerrilla, y de la imperiosa necesidad de contrarrestarla a cualquier precio, ignoraba que la dura represión suscitaría una resistencia aún más enconada de los hispano-dominicanos. Entre las ventajas prometidas a quienes permaneciesen fieles a Francia figuraba la reducción de la presión fiscal.

47 SÁNCHEZ RAMÍREZ: Diario..., p. 56.
} 
se le rompió el fuego". ${ }^{48}$ Sorprendido por el fuego de la artillería y la carga de la caballería patriota, el ejército francés se deshizo y sus hombres huyeron en desbandada. También entonces Juan Sánchez demostró sus dotes de mando y su sentido de la estrategia: prohibió a sus soldados que persiguiesen a los franceses sin orden, ya que podrían convertirse en un objetivo débil, siempre y cuando el ejército enemigo fuese capaz de reorganizarse y de contraatacar en campo abierto. Sólo un cuerpo de cincuenta dragones, comandando por el general Pedro Santana, persiguió al general Ferrand, que había emprendido la retirada desesperada hacia la capital. Durante cuatro horas los enemigos le hostigaron y Ferrand pudo resistir los envites, pero perdió muchos hombres en su huida.

Finalmente, bien porque era consciente de que la capital estaba aún muy lejos y jamás podría alcanzarla, o bien avergonzado por el ridículo estrepitoso de su ejército en la batalla de Palo Hincado, Ferrand se suicidó. ${ }^{49}$ Cuando el general Santana halló su cadáver lo decapitó y entregó la cabeza a Juan Sánchez como trofeo. ${ }^{50}$ La mayor parte de los soldados franceses que lograron salir con vida fueron capturados o muertos en los montes de los alrededores, de modo que pocos de ellos consiguieron llegar hasta la capital. ${ }^{51}$ La única excepción fueron las tropas del coronel Tomás Ramírez, antiguo subordinado de Ferrand, que se rindió a la superioridad patriota y puso sus armas a disposición de este ejército. ${ }^{52}$

Lejos de dejarse llevar por la euforia, Sánchez se dispuso a reorganizar su ejército, que había sufrido más de cincuenta bajas entre muertos (la minoría) y heridos. Sin duda, era consciente de la importancia de la victoria en Palo Hincado, pero también de que debía aprovechar el desconcierto de los franceses para planear cuidadosamente las próximas acciones de guerra, a menos que quisiera que su reciente triunfo cayese en saco roto. Además, reforzó la vigilancia en los caminos que conducen a Santo Domingo, con el fin de evitar que los franceses se rehiciesen y cortasen el acceso a la capital. Juan Sánchez apeló al auxilio popular para organizar las labores de intendencia, entre las que adquirió una prioridad absoluta la atención de los heridos en Palo Hincado. Con objeto de cuidarlos se crearon hospitales de campaña y la población de los enclaves patriotas proporcionó alimentos; además, Sánchez trató a los heridos

48 SÁNCHEZ RAMÍREZ: Diario..., p. 56. Es llamativa la respuesta “francés” a la pregunta "¿quién vive?", porque se dio en castellano. Posiblemente su autor fue algún hispanodominicano al servicio de Francia. Así se demostraba el éxito parcial de la propaganda francesa entre los dominicanos, parte de los cuales se identificaron con los nuevos gobernantes, hasta el extremo de combatir a su servicio. Ahora bien, es posible que Juan Sánchez consignase aquel grito en castellano en su diario, traduciendo a su propio idioma una expresión extranjera que conocía.

49 LEMONNIER-DELAFOSSE, Jean Baptiste: Seconde Campagne..., pp. 215-216. El oficial señala que, suicidado Ferrand, sus hombres no tuvieron tiempo de recoger y honrar su cuerpo ante el avance de los partidarios de Juan Sánchez, debiendo abandonar el cadáver al despojo por el general Santana.

50 GUILLERMIN: Précis..., p. 71; SÁNCHEZ RAMÍREZ, Diarios..., p. 59; RODRÍGUEZ DEMORIZI, Emilio: Invasiones haitianas de 1801, 1805 y 1822, vol. I, Academia Dominicana de la Historia, 25 ${ }^{\circ}$ Aniversario de la Era de Trujillo, Ciudad Trujillo, República Dominicana: Editora del Caribe, 1955, p. 218.

51 AHN, Estado, legajo 60 C, documento 39. Montes-Saavedra, San Juan de Puerto Rico, 26 de noviembre de 1808 .

52 SÁNCHEZ RAMÍREZ, Diario..., p. 60-62. 
españoles y franceses por igual. ${ }^{53}$ Finalmente, puesto que el camino a Santo Domingo había quedado expedito y convenía ocupar la capital cuanto antes, emprendió una leva generalizada para finiquitar el conflicto de una vez por todas.

\section{Desenlace}

Para obtener la victoria final, fue crucial el apoyo que prestaron a Juan Sánchez varios aliados externos: Gran Bretaña, enemiga acérrima de Francia tras la ruptura de la paz de Amiens (1802), que había calmado la tensión entre ambas potencias momentáneamente; Estados Unidos, cuyo gobierno no estaba dispuesto ni mucho menos a permitir que fuese Gran Bretaña la única potencia que se beneficiase de la solución de la Guerra de Reconquista, en el supuesto de que su desenlace fuese favorable a los rebeldes y contrario a Bonaparte; el gobierno de Haití, dividido desde 1806 en dos estados independientes: el reino negro de Henri Christophe al norte y la república de ciudadanos libres de color (mulatos) de Alexandre Pétion al sur, ambos interesados en desestabilizar a Francia para, más adelante, intentar conquistar el este de la isla; y por último, el gobierno colonial de Puerto Rico, que en sentido estricto era un gobierno extranjero desde la óptica de las autoridades francesas y de aquellos dominicanos que las apoyaban, así como desde el punto de vista legal. ${ }^{54}$

Además, el general en jefe patriota también contó con la ayuda de un destacamento de soldados libres de color, dirigidos por Juan Banby y Pablo Alí. El propio caudillo dominicano reveló la extracción de aquellas tropas:

[...] y formé una Compañía al mando de los morenos Pablo Alí y Juan Bambí (antiguos agraciados de Su Majestad Católica por sus buenos servicios en la guerra anterior con Francia, y el primero acreedor del aprecio del Gobierno por su fidelidad, valor y conocimiento), ofreciéndoles la libertad a nombre de la Autoridad Nacional que representa la Real persona de nuestro Augusto Soberano Señor don Fernando $7^{\circ}$, siempre que permaneciesen comportándose bien; $[\ldots]^{55}$

Su historial, especialmente el de Pablo Alí, induce a pensar que Juan Sánchez se sirvió de ellos por su lealtad a la monarquía española, probada en dos circunstancias críticas: en primer lugar la revolución esclava, cuando en 1793 se unieron al ejército de Carlos IV como "negros auxiliares" bajo la dirección de Jean-François, que combatió a favor de España y contra Francia en Santo Domingo entre 1793 y 1795; en segundo lugar, la paz de Basilea, tras cuya publicación decidieron permanecer en Santo Domingo, pese a que el tratado implicaba su vuelta a la condición esclava, momentáneamente. Además, el hecho de que Juan Sánchez contase con los soldados

53 SÁNCHEZ RAMÍREZ, Diario..., p. 65. Salvando las distancias, la batalla de Palo Hincado surtió un efecto similar a la batalla de Bailén en la España peninsular: evidenció la eficacia de la guerrilla española y fue una de las primeras derrotas del ejército de Napoleón.

54 PINTO TORTOSA, Antonio Jesús: Una colonia en la encrucijada: Santo Domingo, entre la Revolución Haitiana y la Reconquista Española, 1791-1809. Tesis doctoral defendida en la Universidad Complutense de Madrid, 2012, pp. 289-295.

55 SÁNCHEZ RAMÍREZ: Diarios..., pp. 176-177. 
libres de color puede explicarse por la relajación de los prejuicios raciales en Santo Domingo en el tránsito de siglo XVIII al siglo XIX, analizada por Moya Pons. ${ }^{56}$ Este último sostiene que la suavización de dichos prejuicios raciales en la colonia había sido una de las consecuencias de las tensiones fronterizas entre españoles y franceses en la Isla Española. En su opinión, hasta principios del siglo XVIII había existido una marcada jerarquía racial; no obstante, la sociedad hispano-dominicana debió someterse a una acelerada criollización porque la colonia atrajo menor cantidad de inmigrantes blancos peninsulares que el resto de posesiones del Caribe hispano, por lo que el mestizaje entre blancos y negros fue inevitable. Las cifras de población proporcionadas por Franklyn J. Franco hablan por sí solas: en vísperas de la firma de la paz de Basilea, habitaban Santo Domingo 35.000 blancos (entre peninsulares y criollos), frente a los 38.000 libertos (artesanos y jornaleros mulatos) y los 30.000 esclavos. ${ }^{57}$ Marcio Veloz Maggiolo reflexiona sobre el peso paulatino del componente africano en la identidad cultural hispano-dominicana, que contribuyó a articular una sociedad híbrida impensable en la España peninsular, en la que se reinterpretaron y se redefinieron los prejuicios raciales de la sociedad española. ${ }^{58}$

Volviendo a la marcha de la guerra, se daba la paradoja de que, pese a que sólo quedaba la ciudad de Santo Domingo por conquistar para que la victoria de los patriotas hispano-dominicanos fuese total, la fase final de la guerra se prolongó porque los vecinos de la capital ofrecieron una resistencia admirable. Mientras sus condiciones empeoraban por la carestía, al tiempo que el general Joseph de Barquier, sustituto del difunto Ferrand, intentaba ganar tiempo para negociar la rendición en condiciones ventajosas, Juan Sánchez tuvo que resolver otros problemas, sobre todo la insubordinación de algunos oficiales y el deterioro de sus relaciones con el gobierno de Puerto Rico. ${ }^{59}$ Resueltas tales circunstancias adversas, y extenuados los vecinos de la capital tras el largo asedio, el 1 de marzo de 1809 las tropas rebeldes emprendieron un último ataque, que movió al general Barquier a realizar una primera propuesta de tregua, rechazada por Juan Sánchez. ${ }^{60}$

56 MOYA PONS, Frank: Historia colonial de Santo Domingo. Santiago de los Caballeros, República Dominicana: Universidad Católica Madre y Maestra, 1973, pp. 378-381.

57 FRANCO, Franklyn J.: Los negros, los mulatos y la nación dominicana. Santo Domingo: Editora Nacional, 1969, p. 72.

58 VELOZ MAGGIOLO, Marcio: Mestizaje, identidad y cultura. Santo Domingo: Secretaría de Estado de Cultura, 2006. He empleado el concepto de "articulación" en el sentido que le da Stuart Hall, como constitución de un elemento a partir de la unión de varias partes que se cohesionan y se relacionan entre sí por sus diferencias, más que por sus semejanzas; HALL, Stuart: "Race, Articulation, and Societies Structured in Dominance", en Sociological Theories: Race and Colonialism, Paris: UNESCO, 1980, pp. 305-345. El proceso evolutivo de la sociedad dominicana ha sido estudiado detenidamente por Mary Louise Pratt: PRATT, Mary Louise, Ojos imperiales. Literatura de viajes y transculturación, México: Fondo de Cultura Económica, 2010.

59 SÁNCHEZ RAMÍREZ: Diarios..., pp. 90-100.

60 GUILLERMIN: Précis historique..., p. 232. La descripción de la absoluta carestía de los habitantes de Santo Domingo durante el asedio es bastante gráfica: "Que l'on représente 4.000 personnes, dévorant depuis un mois les chevaux, les mules, les ânes, les chiens et les chats, les vieux, les herbes des rues, et quelque peu de manioc qu'il fallait chaque jour aller arracher à l'ennemi avec la baïonette". 
Finalmente, el sentido común se impuso en la mentalidad del ejército patriota hispano-dominicano y se iniciaron las negociaciones para la capitulación, aceptándose incluso la mediación de los representantes de Gran Bretaña en las mismas: ${ }^{61}$ así estos últimos garantizarían a los franceses una salida honrosa y además acudirían a la llamada de estos últimos, que en un último alarde de orgullo se habían negado a firmar el armisticio final con los rebeldes de Juan Sánchez, traidores a su patria (Francia). La buena predisposición de los sitiados a rendirse a Gran Bretaña se demostró el 29 de junio de 1809, cuando una comisión de los habitantes de la ciudad se presentó ante el jefe de las tropas británicas, Christopher Myers, para presentarle sus humildes reclamaciones: la rendición de la guarnición de Santo domingo con honores militares y su posterior evacuación a Francia o a América. ${ }^{62}$ Aceptadas las condiciones impuestas por Gran Bretaña y dispuestos los preparativos para la rendición, Juan Sánchez pasó por alto su papel secundario momentáneo en el punto culminante del conflicto, porque juzgó que lo importante era el resultado final de la guerra, es decir, la expulsión de los franceses de Santo Domingo. La capitulación final acabó haciéndose efectiva el 7 de julio de 1809, tras una ceremonia simbólica en la que patriotas hispanodominicanos y soldados británicos enarbolaron los pabellones inglés y español en el Fuerte de San Carlos, frente a Santo Domingo, y profirieron vítores a Fernando VII y Jorge III, para señalar así su alianza en la lucha contra la dominación francesa en el este de aquella isla. ${ }^{63}$

\section{Conclusión}

La documentación y los datos empleados resultan esenciales para demostrar que, si los españoles dominicanos permanecieron fieles a la Corona española pese a la "traición" de la paz de Basilea, fue porque preservaron sus señas de identidad hispana: sobre todo su lealtad al rey y también su fe católica, su lengua y su conciencia de pertenecer al mismo ente territorial que el resto de españoles. Desde 1795 hasta 1808 acataron la administración francesa, cuya instauración interpretaron como el fruto de la voluntad de Carlos IV, quien había dispuesto que se convirtiesen en ciudadanos franceses. Así pues, hicieron alarde de un admirable instinto de supervivencia, aceptando el gobierno francés como un mal menor, siempre que les permitiese alejar la amenaza de invasión de Santo Domingo por los antiguos esclavos de Saint-Domingue. Incluso acataron el gobierno del ex esclavo Toussaint Louverture, que durante

61 LEMONNIER-DELAFOSSE, Jean Baptiste: Seconde Campagne..., p. 233. Este testimonio es interesante, porque el oficial Lemonnier-Delafosse achaca la mediación británica a la apatía de los dominicanos, incapaces de entenderse con el ejército británico y orgullosos hasta el extremo de desear únicamente la rendición incondicional del gobierno francés en Santo Domingo. Por el contrario, los soldados de Gran Bretaña, como se dice en este documento, preferían una salida honrosa para ambas partes, conscientes de que de esta manera se conseguiría la rendición de manera más rápida.

62 TNA, Colonial Office 137/126, pp. 281.282. Comunicado de Christopher Myers al general Carmichael. Cuartel general británico [Fuerte de San Carlos], 29 de junio de 1809.

63 TNA, Colonial Office 137/126, p. 317. Capitulación francesa ante Gran Bretaña y España, por este orden. [Fuerte de San Carlos], 7 de julio de 1809; SÁNCHEZ RAMÍREZ: Diarios..., pp. 226-235; GUILLERMIN: Précis historique..., pp. 336-344; RODRÍGUEZ DEMORIZI: Invasiones haitianas..., pp. 221-222. 
un año (1801-1802) convirtió a toda la isla en posesión negra, haciendo realidad las peores pesadillas de los hispano-dominicanos.

Cuando Jean-Louis Ferrand se hizo cargo del gobierno de Santo Domingo un año después, en 1803, pudo haber considerado que ya había transcurrido tiempo suficiente y que Francia había brindado protección considerable a los hispano-dominicanos (por ejemplo, expulsando a Toussaint Louverture) como para tener la lealtad sincera de estos últimos, de una vez por todas. De este modo, se explicaría su sorpresa cuando en 1808 constató que no era así: cuando los españoles peninsulares se sublevaron contra Bonaparte en mayo de 1808 y, lo que es más importante, cuando aquellas noticias llegaron a Santo Domingo, los habitantes de la colonia creyeron llegado su momento para sublevarse contra el gobierno francés. Ferrand había pecado de excesiva ingenuidad: había sido incapaz de percatarse de que un gobierno como el de Francia, que había intentado potenciar la riqueza de Santo Domingo, puede suscitar gratitud, pero jamás la lealtad de los habitantes de aquel territorio, cuya identidad se había forjado en el último siglo y medio en el odio a Francia. Por tanto, se necesitaba más que benevolencia para convencer a los españoles dominicanos de que eran ciudadanos franceses. ${ }^{64}$

Así se descartan los postulados de Roberto Cassá o Emilio Cordero Michel, convencidos de que los orígenes de la "nación dominicana" pueden rastrearse en los momentos inmediatamente posteriores a la firma de la paz de Basilea. Desde mi punto de vista, la paz de Basilea concienció a los dominicanos de que debían defenderse de las amenazas externas por sí mismos, sin aguardar el auxilio de la metrópoli, que se había revelado incapaz de asistirles en momentos críticos. Esta conciencia pudo ir ligada a un cierto sentimiento autonomista, pero jamás a planteamientos de carácter nacionalista: los españoles dominicanos eran conscientes de que cualquier experiencia independentista iba a poner a Santo Domingo en una posición demasiado débil, convirtiéndola en una presa fácil para Haití. De esta forma, el nacionalismo dominicano ni siquiera se definió en este momento a nivel meramente ideológico; de lo contrario, en el verano de 1808 los españoles dominicanos habrían buscado una salida distinta a la restauración de la soberanía española.

Una década más tarde sólo los abusos del nuevo gobierno colonial restaurado en 1809, sumados a la crisis interna de España, alentó un sentimiento independentista, que cristalizó en la iniciativa de José Núñez de Cáceres en 1821. Su brevedad y su fatal desenlace, la invasión haitiana de 1822, que convirtió a toda la isla en República de Haití durante veintidós años, pusieron de manifiesto dos circunstancias: por una parte, ahora sí, a partir de 1809, el desgaste del gobierno colonial español y la consiguiente decepción con el mismo habían reforzado la identidad dominicana y el deseo de caminar al margen de la metrópoli; por otra parte, desde el punto de vista militar y político, quedaba claro que la independencia aún no podía cristalizar, porque para ello se precisaba una infraestructura estatal fuerte y capaz de hacer frente a amenazas externas como la haitiana.

64 PICÓ: One Frenchman... El historiador insiste también en el interés frustrado de Ferrand por convertir a toda la colonia de Santo Domingo en una colonia francesa, en el más amplio sentido de la expresión. 


\section{Referencias bibliográficas}

ÁLVAREZ JUNCO, José: Mater Dolorosa. La idea de España en el siglo XIX, Madrid, Taurus, 2001.

ANDERSON, Benedict: Imagined Communities. Reflections on the Origin and Spread of Nationalism, London - New York, Verso, 1991.

ARTOLA, Miguel: "La guerra de Reconquista de Santo Domingo (1808-1809)", Revista de Indias, Madrid, LI/191 (1951), pp. 447-484.

- La burguesía revolucionaria (1808-1875), "Historia de España”, vol. 5, Madrid: Alianza, 1990.

CASSÁ, Roberto: "Les effets du Traité de Bâle", en Alain YACOU (dir.): Saint-Domingue espagnol et la révolution nègre d'Haïti. Commémoration du Bicentenaire de la naissance de l'état d'Haïti (1804-2004), Paris - Pointe-à-Pitre, Karthala CERC, 2007, pp. 203-210.

CORDERO MICHEL, Emilio: "Toussaint en Saint-Domingue espagnol”, en Alain YACOU (dir.): Saint-Domingue espagnol et la révolution nègre d'Haïti. Commémoration du Bicentenaire de la naissance de l'état d'Haïti (1804-2004), Paris Pointe-à-Pitre, Karthala - CERC, 2007, pp. 251-258.

- "El primer intento independentista dominicano y la reincorporación a España, 1808-1809", Clio, 79/180 (2010), pp. 123-146.

ESCOLANO GIMÉNEZ, Luis Alfonso: "La guerra de Reconquista en Santo Domingo (1808-1809): una lucha por la continuidad histórica", Boletín del Archivo General de la Nación, XXXIV/125 (2009), pp. 635-659.

FONTANA I LÁZARO, Josep, La época del liberalismo, "Historia de España", vol. 6, Barcelona: Crítica, 2007.

FRANCO, Franklyn J.: Los negros, los mulatos y la nación dominicana. Santo Domingo: Editora Nacional, 1969.

GIMBERNARD, Jacinto: Historia de Santo Domingo, Madrid: M. Fernández y Cía., 1978.

GONZÁLEZ CALLEJA, Eduardo: “España 'Boba', España 'Cavalera' y España 'Madre y Maestra': las relaciones hispano-dominicanas en la conformación de as respectivas identidades nacionales", Clio, 80/182 (2011), pp. 227-248.

GUILLERMIN, Gilbert: Précis historique des derniers événements de la partie de l'est de Saint-Domingue, depuis le 10 août 1808, jusqu'à la capitulation de SantoDomingo, Paris, Chez Arthus-Bertrand, 1811.

GUERRA, Adriano Israel: "Las paradojas de la soberanía y el poder: Santo Domingo durante la Revolución Haitiana y su representación en las Cortes de Cádiz", Clío, n. 81/184 (2012), pp. 11-98.

HALL, Stuart: "Race, Articulation, and Societies Structured in Dominance", en Sociological Theories: Race and Colonialism, Paris: UNESCO, 1980, pp. 305-345.

HOBSBAWM, Eric: Naciones y nacionalismo desde 1780, Barcelona: Crítica, 2000.

LA PARRA, Emilio y LARRIBA, Elisabel (eds.): Manuel de Godoy. Memorias, Alicante: Universidad de Alicante, 2009. 
LEMONNIER-DELAFOSSE, Jean Baptiste: Seconde Campagne de Saint-Domingue. Du ler Décembre 1803 au 15 Juillet 1809, Havre: Imprimerie de H. Brindeau \& Compagnie, 1846.

MOYA PONS, Frank, Historia colonial de Santo Domingo, Santiago de los Caballeros: Universidad Católica Madre y Maestra, 1973.

- "Casos de continuidad y ruptura: la revolución haitiana en Santo Domingo (17891809)", en Germán CARRERA DAMAS (dir.), La crisis estructural de las sociedades implantadas, "Historia general de América Latina", vol. V, París: Editorial UNESCO, 2003, pp. 133-157.

PICÓ, Fernando: One Frenchman, Four Revolutions: General Ferrand and the Peoples of the Caribbean, Princeton - New Jersey: Marcus Wiener Publishers, 2012.

PINTO TORTOSA, Antonio Jesús: Una colonia en la encrucijada: Santo Domingo, entre la Revolución Haitiana y la Reconquista Española, 1791-1809. Tesis doctoral defendida en la Universidad Complutense de Madrid, Madrid: Universidad Complutense de Madrid, 2012.

- "La cultura popular hispano-dominicana ante la paz de Basilea: las décimas de Meso Mónica", Bulletin of Hispanic Studies, Liverpool, n. 98/8 (2013), pp. 921944.

PRATT, Mary Louise, Ojos imperiales. Literatura de viajes y transculturación, México: Fondo de Cultura Económica, 2010.

RODRÍGUEZ DEMORIZI, Emilio: Invasiones haitianas de 1801, 1805 y 1822, vol. I, Academia Dominicana de la Historia, 25 Aniversario de la Era de Trujillo, Ciudad Trujillo, República Dominicana: Editora del Caribe, 1955.

ROUSSEAU, Jean-Jacques: Del contrato social: sobre las ciencias y las artes; sobre el origen y los fundamentos de la desigualdad entre los hombres (ed. Mauro Armiño). Madrid: Alianza, 2002 [1762].

SÁNCHEZ RAMÍREZ, Juan: Diario de la Reconquista, proemio y notas de fray Cipriano de Utrera, Ciudad Trujillo, República Dominicana: Editora Montalvo, 1957.

SPINOZA, Benedictus de: Tratado teológico político (ed. de Julián de Vargas y Antonio Zozaya). 3 vols. Madrid: Sociedad General Española de Librería, 1935 [1670].

VELOZ MAGGIOLO, Marcio: Mestizaje, identidad y cultura. Santo Domingo: Secretaría de Estado de Cultura, 2006. 